\title{
Development of Buddhist Self-Defense Mechanism Model of School Administrators under Office of Secondary Educational Service Area
}

\author{
Suwanna Sudpruk ${ }^{1}$, Phramaha Yannawat Thitavaddhano ${ }^{2}$, Lampong Klomkul ${ }^{3}$, Uthai Satiman ${ }^{4}$ \\ ${ }^{1,2,3,4}$ Faculty of Education, Mahachulalongkornrajavidyalaya University \\ 10ay.suwanna@gmail.com, ${ }^{2}$ yannawat.bud@mcu.ac.th, ${ }^{3}$ research.mcu@gmail.com, ${ }^{4}$ Uthaisati@gmail.com \\ Corresponding Author e-mail: research.mcu@gmail.com
}

\begin{abstract}
The purposes of this research article were 1) to study the state of Buddhist self-defense mechanism of school administrators under office of Secondary Educational Service Area, 2) to develop a model of Buddhist self-defense mechanism of school administrators under Office of Secondary Educational Service Area, and 3) to propose a model of Buddhist self-defense mechanism of school administrators under Office of Secondary Educational Service Area. A multiphase mixed methods design was used for research design and was divided into 3 phases. Phase 1 and 2 were designed by using qualitative research and the key informants were 12 school administrators and educators, and the target group of 9 experts in focus group discussion. They were selected by purposive sampling. Phase 3 quantitative research was designed and 435 samples was selected by two-stage random sampling. Data were analyzed using descriptive statistics, and the research hypothesis was validated the causal model by LISREL program. Results showed that 1) the state of Buddhist self-defense mechanism of school administrators under office of Secondary Educational Service Area found that school administrators perform the ability of school management, being a leadership, being a good role of model both in self-practice and working, being an appropriate position. There were 3 main important components which consisted of (1) best performance of management related to good role of model in Buddhist self-defense mechanism, (2) communication language of management related to speech honesty in Buddhist self-defense mechanism, and (3) management method for ultimate goal related to public mind in Buddhist self-defense mechanism. 2) The developed model of Buddhist self-defense mechanism of school administrators under Office of Secondary Educational Service Area showed that components of important factors and was a causal relationship. Results towards to Buddhist self-defense mechanism of school administrators consisted of self-defense mechanism and urgent wisdom management. Results of model assessment showed that it was possibility, correctly, and appropriately model. 3) A causal relationship model of Buddhist self-defense mechanism of school administrators under Office of Secondary Educational Service Area was fit with empirical data. Analysis results were Chisquare $=21.25, \mathrm{df}=14, \mathrm{p}=.095, \mathrm{GFI}=.992, \mathrm{AGFI}=.995, \mathrm{RMR}=.011$, accounting for the variations in urgent wisdom management was 84.80 percent and in Buddhist self-defense mechanism was 87.20 percent. Therefore, self-defense mechanism and urgent wisdom management can be encouraged to initiate Buddhist self-defense mechanism of school administrators.
\end{abstract}

Index Terms

Self-Defense Mechanism, School Administrators, Secondary Educational Service Area

Article Received: 10 August 2020, Revised: 25 October 2020, Accepted: 18 November 2020

\section{Introduction}

Education is to educate people and able to have the basic skills necessary to have a good character. They are ready to fight for themselves and for society are ready to pursue a career education helps people to flourish, both mentally, mentally, and physically, and can also affect society and the nation to prosper and advance as well as the civilization. In National Education Act, the revised edition of 1999 said that to develop Thai people to become a complete human being, physically, mentally, intellectually and socially, having morality, ethics and culture of living, able to live happily with others according to the educational law's aim. National B.E. 2542 (1999) and Amendment (No. 2), B.E. 2545, section 6 has an important principle in the provision of education, that is, life-long education for the people, allowing society to participate in education management, with continuous development of knowledge and processes (section 8) encourage teachers to organize the atmosphere, environment, learning materials and facilitate learning (section 24) [1] in which the said education takes place in more than 38,629 schools in Thailand. The school is an agency that is responsible for educational management and performing various tasks in order to promote learning and teaching which is beneficial to the learners including organizing various activities that nurture and instill students to be good citizens of society have good cultural and social values under the leadership of the school administrators so, administrators play an important role in education administration and management. It possesses important attributes, both professional and personal, to pursue the achievement of the goals and objectives of the study. The modern school administrators will be the leaders of the change in the management paradigm. Therefore, the capacity of the current school administrators must be the leaders and adapt to keep up with the changes that will occur. Professionals, such as adapting to keep up with the technology age including adjustments when moving to schools since most administrators tend to transfer schools frequently. Thus, there must be an adjustment to the organizational culture, personnel, number of students, places, as well as adaptation to cope with various situations. It is the adjustment of body and mind to live in society. In the environment and in various situations happily from the context of the adaptation mentioned above which management has to face and cope properly in psychology, adaptation is a movement in which a person behaves. To meet the physical, mental and social needs, the body reacts in different ways, known as the Defense Mechanism [2], where the defense mechanism is strategies that humans use 
to mitigate the emotional states that arise by distorting, denying and avoiding situations. Once used, the person will feel more comfortable to be able to maintain a balance in the mind to some extent, but if used to everything until it becomes habitual, it can negatively affect personality. Because the defensive strategy itself is to fight and protect yourself from unacceptable reality situations. Therefore, if used a lot It may cause the person to have a personality that cannot accept the truth of what happened to him. [3] In Buddhism, there are many principles of Buddhism suitable for self-defense which can be used continuously without any negative effect on the user, such as the Four Noble Truths, Trisikkha, Ayatana VI, and Satipatthana IV, etc., where the principles that are suitable to be integrated for self-defense are the practice of mindfulness by means of practicing mindfulness according to Buddhist principles is called the four mindfulness. Mindfulness is remembrance, remembering, not being unconcerned, controlling one's mind or holding one's mind with related things. Body with work mind on work caution, vigilance, duty, a state that is always ready to be aware of things, [4] Jung can be able to reduce the use of self-defense strategies or make it less.

From the background and importance of the problem, the researcher is interested in studying development of a Buddhist Mechanism Model of School Administrators under the office of the Secondary Educational Service Area about what types of strategies there are and how many executives do to guide self-improvement in the area of adaptation. The use of strategies will affect personality including the efficiency of the school administration as well.

\section{Research Objectives}

The purposes of this research article were 1) to study the state of Buddhist self-defense mechanism of school administrators under office of Secondary Educational Service Area, 2) to develop a model of Buddhist selfdefense mechanism of school administrators under Office of Secondary Educational Service Area, and 3) to propose a model of Buddhist self-defense mechanism of school administrators under Office of Secondary Educational Service Area.

\section{Research Methods}

A multiphase mixed methods design was used for research design and was divided into 3 phases [5], divided into 3 phases:

Phase 1: In-depth interview to study the Buddhist mechanics of the school administrators under the Office of the Secondary Educational Service Area. The target group is experts in school administration. The data were collected from purposive sampling of 12 key informants. The tool used for data collection was interview question guidelines. The issues involved include 1) self-defense strategies, 2) management with knowledge and knowledge, 3) Buddhist principles of the school administrators. In this phase 1 research, the qualitative research was analyzed by creating an inductive conclusions (analytic induction) in which the results of the analysis would answer the research objective of item 1. The results obtained from the research in Phase 1 were gotten the Buddhist mechanics of the school administrators under the office of the Secondary Educational Service Area.

Phase 2 Focus group discussion to develop a Buddhist mechanics model of school administrators under the Secondary Education Service Area Office. The target groups used in the discussion group are scholars of Buddhist education administration. Education management expert using purposive sampling of 9 experts, the focus group discussion tool consisted of two parts of the group discussion concept or issue as follows: Part 1: components of the development of the Buddhist Mechanism model of school administrators under the Secondary Education Service Area Office, section 2, issues used in examining the feasibility and feasibility of the development of a Buddhist mastering mechanics model of the school administrators under the Office of the Secondary Educational Service Area. The analysis of the data in phase 2 will be conducted in the same way as the phase 1 , where the results of the analysis will satisfy the research objective of item 2 . Buddhist teaching of the school administrators under the Office of the Secondary Educational Service Area.

Phase 3 Questionnaire to present the Buddhist mechanics model of the school administrators under the Office of the Secondary Educational Service Area in phase 3, using a quantitative method. The quantitative approach was obtained by using data from the second phase of the study to develop a causal relationship model showing the Buddhist mastery of the school administrators under the Secondary Education Service Area Office and to verify the validity of the developed causal relationship model, the sample size was determined using the formula of Hair and others, [6] a sample size of 15 people per 1 parameter was used; The sample consisted of 435 people. The instrument used for data collection was a questionnaire. The third phase consisted of data analysis: Analysis of reliability using Cronbach's alpha coefficient formula analyze structural straightness using affirmative element analysis Confirmatory Factor Analysis: (CFA), 2) Preliminary data analysis, namely, preliminary statistical analysis of the variables related to the background of the sample using frequency and percentage. The observable variables were analyzed by using the computer package program. The statistics used were mean $(\overline{\bar{x}})$, standard deviation (SD), distribution coefficient (CV), skewness, kurtosis, and the distribution characteristics of variables and a correlation analysis with computer software; analyzed SEM to investigate model straightness and influence size analysis to study variables in the causal relationship model. Buddhist mechanics model of school administrators under the Office of the Secondary Educational Service Area according to the research objective of item 3 and the results obtained from the research in phase 3 , the Buddhist mechanics model of the school administrators was obtained under the Office of the Secondary Educational Service Area.

\section{Results}

1. The results of the synthesis of the Buddhist mechanics of the school administrators under the Office of the Secondary Educational Service Area in the context of educational institutes, administrators and scholars of Buddhist education administration were interviewed from the following 3 
issues: 1) the self-defense mechanism, 2) the management with knowledge, and 3) in the Buddhist-based strategy of the school administrators, the research results were found that 1) Self-Defense Mechanism Executives act according to the policy set goals or objectives operational planning create a calendar of operations have a cooperative meeting management with Quality Cycle (PDCA) has a solution to problems by considering specific problems according to the situation finding the cause of the problem analyze the problem meeting and consultation for all parties find a solution on the issue of conflicts, the issue is mediated by perseverance and having a model in management that can be applied in their own administration. 2) In Management with intelligence, Executives have a good position play the role of leader or follower appropriately can be a model for others and reasonable always in mind not enslaved by emotions use the principles of cutting off defilement and provocation hold on to the good must not allow opportunities for passion practicing mindfulness, mind control, and having the principles of mind used in administration; executives are sufficient. Act as a good role model take responsibility for yourself use clear, polite language, semi-formal language, two-way communication language focus on management for maximum benefit consider school interests and have a public mind.

2. Results of the development of a Buddhist mechanics model of the school administrators under the Office of the Secondary Educational Service Area.

The researcher designed the study to develop a Buddhist mechanics model of the school administrators under the Office of the Secondary Educational Service Area using focus group discussion by Buddhist scholars in educational administration. In education management expert, the research results were found that Buddhist mechanics model of school administrators. The developed secondary education service area office has important factors and has a causal relationship. The results that will lead to the Buddhist principles of the school administrators include 1) selfdefense strategies, and 2) management with knowledge and the results of the examination showed that there is a possibility is correct and suitable.

3. The results of the presentation of the Buddhist mechanics model of the school administrators under the Office of the Secondary Educational Service Area by examining the validity of the developed causal relationship model and the analysis of direct and indirect influences between the variables in the model. The results of preliminary statistical analysis of variables used in the Buddhist mechanics model of school administrators under the Office of the Secondary Educational Service Area in all 3 areas, it was found that the average was at the high level of all. When considering the skewness value, it was found that most of them had a negative skewness value, indicating that the data of all the variables was above the mean when looking at the kurtosis $(\mathrm{Ku})$, it was found that all variables had a high-altitude distribution curve lower than the normal curve. The distribution coefficient (C.V.) showed that all the variables had a large distribution of the data, and when considering the distribution coefficient (C.V.), the data were similar. There is little distribution of information as in Table 1 as follows:
Table 1 Initial statistical values of observed variables in a causal relationship model showing influence of Buddhist mechanics model of school administrators under the Secondary Education Service Area Office $(\mathrm{N}=435)$.

\begin{tabular}{c|c|c|c|c|c}
\hline \hline $\begin{array}{c}\text { Buddhist mechanics } \\
\text { model of school } \\
\text { administrators Under the } \\
\text { Office of the Secondary } \\
\text { Educational Service } \\
\text { Area }\end{array}$ & Mean & S.D. & Sk & Ku & C.v. \\
\hline $\begin{array}{c}\text { Self-defense } \\
\text { mechanics }\end{array}$ & 4.63 & 0.46 & -1.44 & 1.65 & 9.95 \\
\hline $\begin{array}{c}\text { Management with } \\
\text { intelligence and } \\
\text { knowledge. }\end{array}$ & 4.52 & 0.46 & -0.74 & -0.53 & 10.22 \\
\hline $\begin{array}{c}\text { Buddhist mechanics } \\
\text { of the school } \\
\text { administrators }\end{array}$ & 4.65 & 0.46 & -1.39 & 1.18 & 9.91 \\
\hline \hline
\end{tabular}

The results of the analysis of the relationship between the observed variables of the Buddhist mechanics model of the school administrators under the Office of the Secondary Education Service Area, the analysis results showed that Bartlett's Test of Sphericity, which is a hypothesis test statistic that the identity matrix has a test statistic of $5752.745(\mathrm{p}=.000)$, indicating that the correlation matrix between all observed variables of the sample is significantly different from the identity matrix. The statistical significance at the .01 level and the Kaiser-Meyer-Olkin Measure of Sampling Adequacy (KMO) index were .913 with an approach of 1 indicating that the variable in the correlation between these data sets is appropriate for further analysis of the SEM model.

When considering the correlation between 12 observable variables, it was found that the correlation between the variables with a statistically significant difference from zero $(\mathrm{p}<.01)$ was 66 pairs with a range of correlation coefficients in the range of 0.481 . to .839 , when considering the correlation of observable variables, it was found that all were statistically significant $(p<.01)$ and was positive, indicating that the correlation of all variables was in the same direction.

The results of the consistency analysis with empirical data of the Buddhist mechanics model of school administrators have 3 latent variables under the Secondary Education Area Office in the data analysis: Self Defense Mechanism (SELFD), Cognitive Management (MANAW), Buddhist Principle of Education (BDFA). Twelve observable variables were used in the data analysis when considering the results of the Buddhist mechanics model analysis of the school administrators under the Office of the Secondary Educational Service Area found that the model is consistent with the empirical data. The statistic used to verify the consistency between the model and the empirical data was that the chi-square was 21.25 degrees of freedom equal to 14 , the probability (p) was .095 , that was, the chi-square difference, significantly different from the center, indicating that the main assumption that the Buddhist mechanics model of the school administrators under the Office of the Secondary Educational Service Area developed in harmony with empirical data corresponding to the analysis results, the harmonization index (GFI) is .992, the modified harmony 
index (AGFI) is .995 , which is closer to 1 and the root of the mean square index. The remainder (RMR) is .011, which approaches zero and the remainder in the form of the Largest Standardized Residuals score of 3.131, supporting that the research model is consistent with the empirical data as shown in Fig. 1.

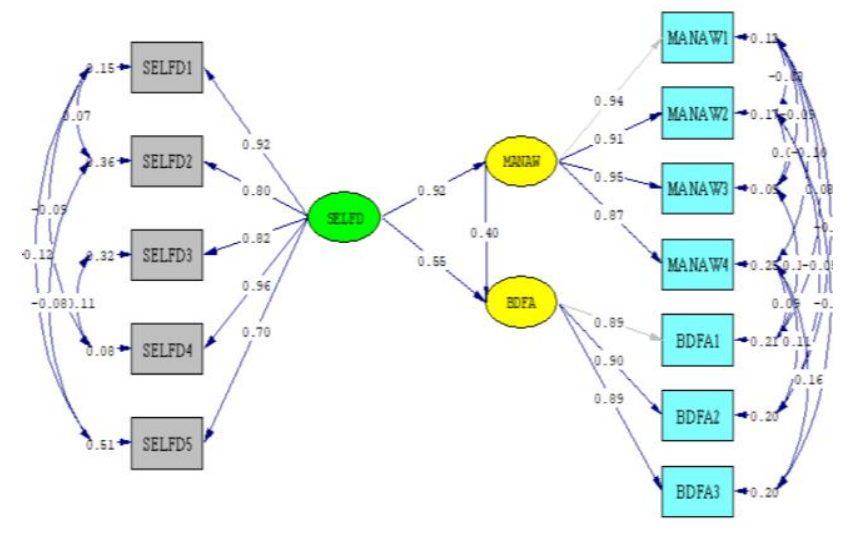

Chi-Square $=21.25$, df $=14$, p-value $=0.09537$, Rusea $=0.035$

Fig. 1 Causal relationship model, Buddhist mechanics of the school administrators Under the Office of the Secondary

Educational Service Area.

\section{Discussions}

The researcher found important points to discuss the results of the development of the Buddhist mechanics model of the school administrators under the Office of the Secondary Educational Service Area as follows :

1. The Buddhist mechanics of the school administrators Under the Office of the Secondary Education Area found that the self-defense mechanism school administrators have successful administration. as a self-defense strategy corresponds to the defense mechanisms that achieve maturity with defined operational goals or objectives. There is a job assignment to colleagues with clearly divided work duties using a management process with the PDCA quality cycle, there is adaptation during the operation and pride when managing successfully guidelines for solving problems in administration as a self-defense strategy corresponding to the defense mechanism against the situation encountering problems and obstacles during the administration, the executives can adapt to face them very well. There are solutions to problems in the administration. Able to face various situations calm your mind first, and then analyze to find the root cause of the problem meetings are held to discuss, plan and brainstorm find a solution including applying the royal science to apply in solving problems. Management of conflicts within schools as a selfdefense strategy corresponding to a compromise defense mechanism administrators can deal with conflicts within the school. Manage problems with compromise, have patience, work patience listen to colleagues' thoughts and reasons, able to coordinate with all parties direction of administration within the school as a self-defense strategy corresponding to the predictive protection mechanism. Management has forecasting or planning ahead of operations, set the direction of administration within the school and create a calendar of operations. Plan for the stresses that will arise in the future and have a careful planning of how you face them. Master in
Administration as a self-defense strategy corresponding to the anti-mimic mechanism has a role model in administration apply managerial principles and good speaking techniques from others, apply good ideas from model people adjust the personality to be similar to the model. This is related to the concept of simulated and moderated Dithavanij that the mature defenses are psychological mechanisms considered to be the highest level corresponding to level I in DSM-IV. Adaptation and being in soundness of mind often contributes to dignity. Pride of oneself and forecast (anticipation) forecasts or planning ahead rationally [7] and in accordance with Tanyapat Lertchantarakun which discusses the types of self-defense strategies Situationalism refers to a way of adapting to a problem situation and the compromise type of situation is a mechanism that has a semi-meeting manner fight, not escape, not really, so it is a form that is expressed by choosing a new method change needs or goals [8].

The management with intelligence and knowledge (Satipatthana IV), the school administrators have placed themselves during their duties. It is management with intelligence and knowledge being consistent with being intellectual, cognizant of the physical condition, being mindful of self-control and display appropriate behavior, be in good shape during your duties, perform appropriate roles of leaders and followers can be a good role model for others dealing with situations that affect feelings. It is management with intelligence and knowledge. Being consistent with having intelligence, knowing the feelings conscious over his own feelings able to deal with situations that affect feelings understand and adjust your emotions to be able to accept what happens in different situations. There are ways to relieve stress in the workplace, patience, and calm able to control emotions dealing with situations that cause passion is an intelligent management. Being consistent with having wisdom, knowing the state of mind. Be conscious and restrained recognizing himself to be conscious of relieving desire deal with situations that cause passion adhere to the good, follow the rules use wisdom in reflection and not go along with temptation, principles of mind used in administration. It is management with intelligence and knowledge, being consistent with having intelligence, knowing the truth of management Stay mindful while performing duties use the principles of management behave in good morals use the principle of self-control, occupation and occupation in management, being responsible for his own duties, which is in line with the concept of Chakraphong Paiboon said that the place of consciousness is the place of consciousness, meaning that remembrance is aware of the four consciousness, which is to remember the four things: body, mindfulness, supervision. Look at being self-conscious and the physical of pity is the feeling of happiness; Mindfulness, directing, being aware of the mind, or the state and symptoms of spirituality, is the Buddha's teaching. Consciousness, determination, judgment, or mindfulness, supervision, looks being simple [9].

Buddhist mechanics of the school administrators outstanding management is a Buddhist strategy of the school administrators corresponds to a good prototype do their duty perfectly have knowledge and management ability. Having leadership in management and able to be a model for others both in selfpractice and performance appropriate as an executive 
management language is a Buddhist strategy of the school administrators corresponds to the words of honesty is a rhetorical executive communicate in polite words use friendly language during work. Being truthful in keeping your word use words that create harmony in the workplace, how to manage work for maximum benefit is a Buddhist strategy of the school administrators. Being consistent with having a public mind, that is, to perform one's duty with full willingness and strength to sacrifice one's happiness for the common good using both science and art in management for maximum benefit regularly participate in volunteerism and public interest activities and adhere to morality and ethics which is in line with the concept of Sunthorn Kothatyai said that professional education administrators in the education reform era, there should be some basic characteristics: must be a visionary, able to analyze the situation (analyze situation) to formulate a strategic plan and an action plan to achieve goals and policies appropriately have the ability to manage human resources is a good example in behavior for letting the subordinates use it as a role model and not use their positions and duties to seek benefits for themselves regardless of being directly or indirectly [10].

2. Development of a Buddhist Mechanism Model of the School Administrators under the Office of the Secondary Educational Service Area consists of 3 important elements as follows: Component 1: Self-Defense Mechanism has 5 main principles, consisting (1) Maturity protection mechanism, (2) Antisituational defense mechanism, (3) compromise defense mechanism, (4) Predictive defense mechanism, (5) Anticounterfeiting mechanism, Component 2: Management with intelligence, know-how, has four main principles, which are: (1) Intelligence, knowledge of the physical condition, (2) Intelligence, cognizance, feelings (3) Intelligence, knowledge of the mind, (4) Knowledge keeps up with the actual management Component 3: The Buddhist principles of the school administrators have 3 important principles, which are: (1) good model, (2) Vajesucharit (good conduct in word), (3) public mind, whose research results are consistent with some findings in the research. Surat Sridadej has researched model of effective administration of basic education institution administrators under the Office of the Basic Education Commission, the results of the research were the four key elements of administration are social system elements, namely the achievement of objectives, integration and preservation of patterns. Service Skills Components Basic school administrators must have essential administrative skills, including ethical skills, academic skills, technological skills, diagnostic skills, communication skills, and political skills. Administrative front elements, the basic duties of the school administrators, consist of process functions such as planning, organizing, the supervisory, leadership, control, and management role elements consist of 3 main roles which are: 1) Personnel Relational Role Group consists of the symbolic role of the organization, organization leadership role, relationship builder role, and the role of the team creator, 2) the information role group consists of the role of supervising and monitoring role of information publisher publicist role and the role of supervisor, 3) The decision-making role group consists of the role of entrepreneur, the role of the disruptor, role as a problem solver, the role of resource allocation, and its role as a negotiator, [11] and is consistent with some findings of the research have studied research on defensive strategies of school administrators. The research results were found that the defensive strategies of the school administrators can be classified into 55 strategies, with some of which have similar meanings or can be combined with other mechanisms. The researcher presented 20 strategies for this research, namely 1) suppression, 2) misrepresentation, 3) betraying others, 4) movement, 5) opposing reaction, 6) regression, 7) selfisolation, 8) fantasies, 9) reversal, 10) mimicry, 11) release 12) prediction, 13) seeing benefit, 14) humor, 15) suppression, 16) use intelligence, 17) compensation, 18) negation, 19) expression of action, and 20) indirect aggression [12].

3. The results of the presentation of the Buddhist mechanics model of the school administrators under the Office of the Secondary Educational Service Area. It was found that the results of the analysis of the Buddhist mechanics model of the school administrators under the Office of the Secondary Educational Service Area found that the model is consistent with the empirical data considering the direct and indirect influences between the variables in the model, it was found that the relationship between the Self Defense Mechanism (SELFD) variable and the Buddhist policy of the school administrators (BDFA) (correlation size $=.920$ ) were classified as direct influence is 552 and indirect influence is .369 which are combined influences is .920 , it was found that direct influence was greater than indirect influence. Therefore, the Buddhist strategy of the school administrators must be managed with intelligence (Master of Mindfulness IV) is a component together with the self-defense strategy. This will result in a Buddhist strategy of the school administrators, namely the good model, Vajesucharit, with public mind as an important part of the school administration in line with the findings of some issues in the research, Sukapinya Srikhamthai conducted a research on the education management model according to the mindfulness principle. This is the application of management concepts in all 3 areas of study, including 1) self-administration is the application of management principles to apply to the education of executive selfmanagement, 2) human management is the application of management principles to be applied Applies to education in management of people, co-workers of the executive, 3) Administration is the application of management principles to apply to the education of management education of administrators. 2. Mindfulness is a collaborative process of mindfulness and wisdom (smallness) is consciousness to let wisdom see by using mindfulness according to the view with wisdom and know as to the truth that happened in all four areas, namely body, feeling, mind and Dhamma, consisting of 1) Kayanupassana (the mind-seeing of the body). Intellectually aware of the physical condition. (Seeing to see compassion) is the use of mindfulness to follow with wisdom, knowing the feeling of happiness and suffering or not happy, not suffering that arises 3) spirituality (Seeing the mind) is the use of consciousness according to the mind, knowing the state of mind and 4) Thammanupasana. (Seeing the Dhamma) is the use of mindfulness according to the view with wisdom and know all the stories that are known to think that occurs in the mind. It is the process of applying administrative principles related to educational administration by integrating with the mindfulness principle to benefit the educational administration of the education administrators are composed of 1) principles, 2) objectives, and 3) processes as a process 
of education administration according to the mindfulness principle by relying on the process of working together of mind and intelligence (smallness) is consciousness to see by using mindfulness according to the wisdom and understanding according to the truth that happened in all four areas, namely Kayanupassana (see body), (See the feelings), the mind, (see the mind) and the Dhammanupatsana (see the Dharma) consist of (1) selfmanagement according to mindfulness 20 principles, is the application of management principles to apply to the study of self-administration. (2) People management according to mindfulness 14 principles is the application of management principles to apply to the education of management of people, associates of the executives. (3) Management according to mindfulness 15 principles is the implementation of management principles to be applied to the education of executive education [13].

\section{Conclusion}

Development of a Buddhist Mechanism Model of School Administrators Under the Secondary Education Area Office, the self-defense strategy refers to the strategies that humans use to reduce their emotional state and keep the mind in a balanced state. There are five elements within the components: the defense mechanism that reaches maturity. Situational defense mechanism compromise defense mechanism. Predictive defense mechanisms and imitation defense mechanisms, which are integrated with intelligent management, refer to mindfulness 4: the location of consciousness. The implication is that there is always consciousness and the principle of mindfulness or the use of mindfulness in the four bases, namely, the body, the mind, the mind, and the Dhamma to know the truth. (Kayanupasana Satipatthana) 2) Wise, be aware of feelings (Vedananupusana Satipatthana) 3) Wise, know as well as mental state. (Consciousness, mindfulness) 4) have intelligence, know-how, management based on reality (Dhammanupasana Satipatthana) will result in a Buddhist strategy of the school administrators, which is a good model, honesty and public mind.

\section{References}

[1] Office of the National Education Commission, National Education Act, B.E.2542, 2nd Edition, Bangkok: Office of Policy, Planning and Standards of Education, Religion and Culture B.E.2545.

[2] N. Nithayayon, adaptation and personality Psychology for Education and Life, Bangkok: Odeon Store, 2016.

[3] T. Kathavanich. General psychology, Bangkok: SE-EDUCATION, 2004.

[4] Phra Promkhunaporn (P.A. Payutto), Buddhist Dictionary, Glossary, 11th edition, Bangkok: SR Printing Mass Products Company Limited, 2008.

[5] P.D. Leedy and J.E.Ormrod, Practical research planning and design. 11th Edition.Essex: Pearson Education Limited, 2015, and Haines, C., Value added by mixed methods research: A Multiphase mixed methods design, The Degree of Doctoral of Philosophy (Psychological Studies in Education), University of Nebraska-Lincoln, 2011.

[6] Hair, J.F. Jr., Anderson, R.E., Tatham, R.L., \& Black, W.C. (1998). Multivariate Data Analysis, 5th Edition, Upper Saddle River, NJ: Prentice Hall, 1998.

[7] C. and P. Disyawanich, Stress, Anxiety and Health, Chiang Mai: Faculty of Medicine, Chiang Mai University, 2002.

[8] T. Lertchantharakun, Personality development Techniques, Bangkok: SEEDUCATION, 2019.

[9] C. Phaibun, Step of Mindfulness, 2nd edition, Bangkok: Tnt., 2009.

[10] S. Kotlawai, Principles and Theories of Educational Administration, Bangkok: Intellectuals, 2011.

[11] S. Sridadet, "Presenting an effective management model for the to manage educational institutions based on Affiliated with the Office of the Basic Education Commission ", Ph.D. Educational Administration, Graduate School: Naresuan University, 2006.

[12] M. Apisakmontri, "Self-Defense Mechanism of School Administrators", Doctor of Philosophy Thesis, Graduate School: Silpakorn University, 2014.

[13] S. Srikhamthai "Educational Administration Model according to Mindfulness Principles", Doctor of Philosophy of Buddhism, Graduate School: Mahachulalongkornrajavidyalaya University, 2019. 